\title{
Creating a New Type of Laboratory Science Practice Teaching Mode by WeChat
}

\author{
Han Wei ${ }^{1}$, Zhang Xiaotong ${ }^{1, ~}$, Fang Rui ${ }^{1,}$, , Song Wenwei ${ }^{1}$, Xia Letian ${ }^{1}$, Li Zhining ${ }^{2}$, Hou Xinwen ${ }^{3}$ \\ ${ }^{1}$ Clinical Laboratory, Xuzhou Mining Group General Hospital, Xuzhou, China \\ ${ }^{2}$ Neurology, Xuzhou Mining Group General Hospital, Xuzhou, China \\ ${ }^{3}$ College of Medical Technology, Xuzhou Medical University, Xuzhou, China
}

Email address:

375165292@qq.com (Zhang Xiaotong),Wfangruix@163.com (Fang Rui)

${ }^{*}$ Corresponding author

\section{To cite this article:}

Han Wei, Zhang Xiaotong, Fang Rui, Song Wenwei, Xia Letian, Li Zhining, Hou Xinwen. Creating a New Type of Laboratory Science Practice Teaching Mode by WeChat. International Journal of Clinical and Experimental Medical Sciences. Vol. 4, No. 5, 2018, pp. 73-77. doi: $10.11648 /$ j.ijcems.20180405.11

Received: September 4, 2018; Accepted: November 9, 2018; Published: December 4, 2018

\begin{abstract}
This paper is aimed at creating a new type of Laboratory Science Practice Teaching Mode by means of WeChat .We will explore innovatively Laboratory Science intern teaching work by means of WeChat combined with the teaching form of "flipping classroom" to change the roles of teachers and students, so as to improve students' learning initiative and autonomous learning ability. In order to make interns during the internship stage have a better sense of responsibility, sense of mission, apply medical knowledge to the future clinical work better and equip themselves with the ability to communicate well with clinics and patients. Therefore, they are able to become a qualified tester who can better serve patients and the clinical service.Establishing and applying laboratory science WeChat planform, the Clinical laboratory of the Second Affiliated Hospital of Xuzhou Medical University has received consistent appreciation from the medical staff and patients after half a year's trial run period. While perfecting Laboratory Science brand, it provides a new service mode for the development of the clinical laboratory, new ideas for the clinical practice teaching mode so that interns of Laboratory Science will have due qualification and ability as a Laboratory Science Major. We believe that with the further development of WeChat platform, Laboratory Medicine will provide more accurate, timely and high-quality service for patients and clinical work.
\end{abstract}

Keywords: WeChat Platform, Filping Classroom, Laboratory Medicine, Innovative Services, Clinical Communication, Practice Teaching

\section{Introduction}

Laboratory Medicine is a medical frontier subject, which is aimed at diagnosis, prevention and treatment of human disease or evaluation of health conditions [1], provides advisory services for clinical departments, including the interpretation of the experimental results and advices for further appropriate check [2]. As a part of the clinical teaching, clinical practice is an important link which enables interns to develop and master clinical skills during a relatively short period, and use theoretical knowledge to analyze question, solve the problem and work independently. However, in recent years, clinical practice teaching is faced with many challenges [3-5].A series of problems, such as how to break through innovation, how to make interns achieve the ability to find and solve problems, and how to develop them into talents of high quality is an extremely important challenge facing hospital's clinical laboratory. Building a Laboratory Science WeChat platform [6-8], our department makes innovative exploration on the internship teaching mode and the "flipping classroom" and other teaching methods have been implemented simultaneously, thereby making them become the protagonist of clinical practice instead of studying passively and have the sense of responsibility and sense of mission, enhancing their quality and ability which is necessary for a tester. 


\section{Materials and Methods}

\subsection{The Current Situation of Laboratory Science Practice Teaching}

In recent years, that various medical colleges and universities expand enrollment, makes the clinical practice teaching resources scarce. Owing to daily work of high pressure, most teaching teachers fail to pay enough attention to clinical practice teaching Mastering the basic test operation, a lot of interns become the main force of department and their enthusiasm for practice gradually fade away in daily work, which weakens their ability of thinking independently, discussing clinical cases, and offering clinical consultation.

Modern test work is mainly focused on establishing detecting system, guaranteeing inspection quality, analyzing the process of test, checking and explain test results, which requires students not only have a comprehensive understanding of Laboratory Science knowledge, but also they master the ability of finding, analyzing and solving problems .It puts forward higher requirements for students' medical thinking and scientific quality as well as practice teaching work. Therefore, how to elevate the enthusiasm of interns, exercise their clinical thinking ability, and guide them to learn independently and actively is the key point of current education reform of laboratory medicine.

\subsection{Designing Concept for Laboratory Science WeChat Platform}

WeChat platform is one of the most popular network service terminals [9-10], gradually integrating into people's lives with its prominent advantages of convenience and novelty. Our department intends to set up inspection service platform of new concept by taking advantage of its powerful function of intelligent terminal. Based on the scientific demonstration of the construction concept of the platform and relevant questionnaire survey, we designed a basic framework for the new platform, as shown in Figure 1.

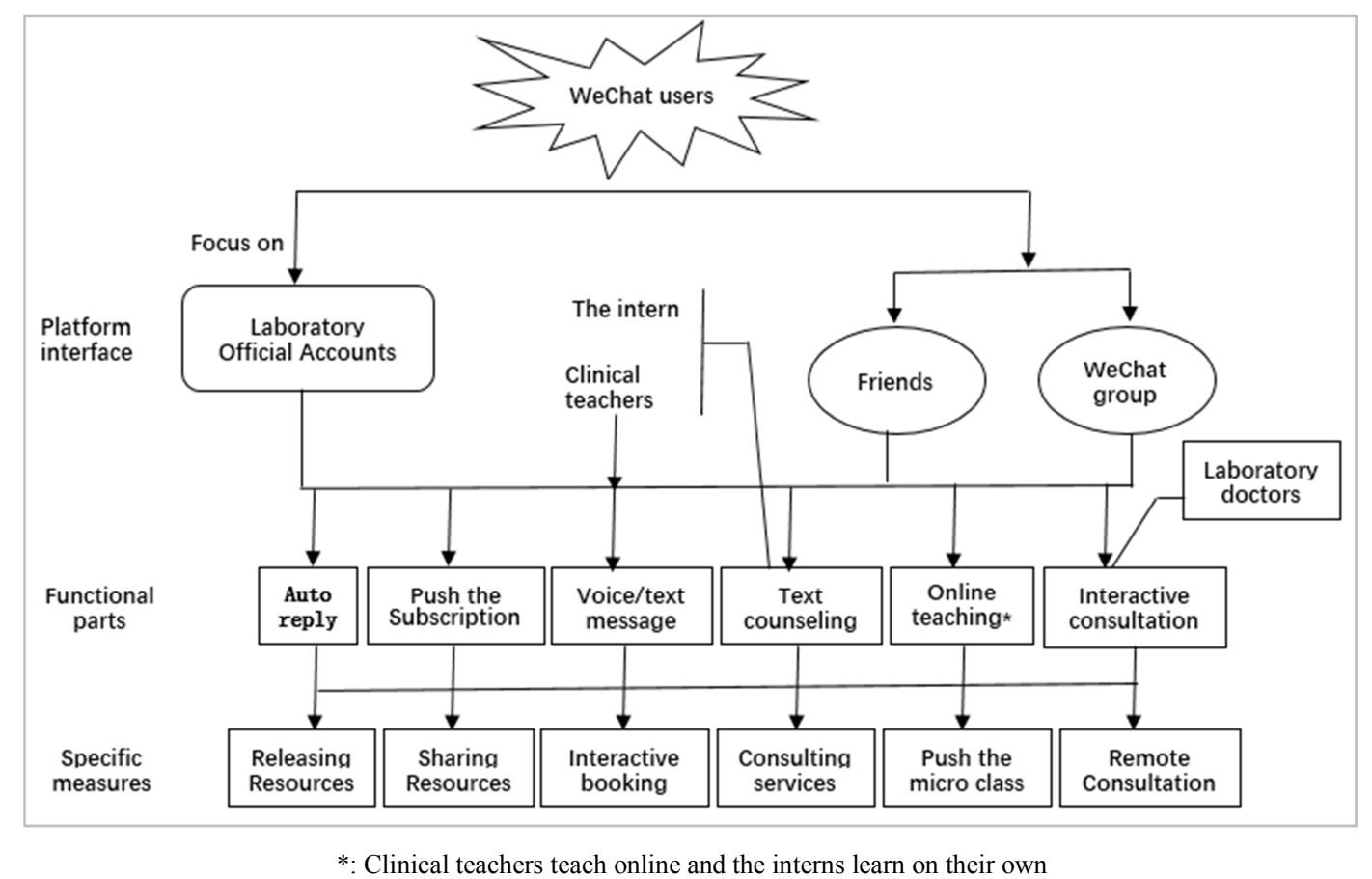

Figure 1. The WeChat platform blueprint of medical laboratory.

Design philosophy of Laboratory Science WeChat platform: public account attention, friends and wechat group interaction. We hope to create internal Laboratory Science service platform by means of WeChat friends and WeChat group, which is helpful to promote closer collaboration and communication between test and clinic, and can timely and accurately offer reasonable suggestions for clinical diagnosis and treatment and relative laboratory medicine support.

\section{The Results}

\subsection{The Extension of Clinical Teaching in WeChat Platform}

With the test platform, the construction concepts of resource release, report reservation query, special test appointment, medical resource sharing, test communication, interactive consultation and other functions can be realized [11-13]. Our department involves interns in WeChat platform management through the access authorization, changes passive to active and orders them to push information about test report consultation, medical medicine knowledge and so on .This can improve interns' clinical practice activity, exercise their clinical thinking ability, and guide students to learn autonomously and actively. While providing consulting services, they can exercise their communication skills with patients and clinic so that they will grow into a good tester in a relaxed and lively atmosphere. As shown in Figure 2. 


\subsection{Laboratory Science Consulting Service}

Laboratory Science consulting service is one of our WeChat platform characteristic services. Its existing pattern is that interns are divided into groups to answer questions, namely immune rotary interns of immune are responsible for answering questions about immunity while biochemical rotary intern students are responsible for the related knowledge of biochemistry. Senior and experienced teachers will take responsibility when interns of all groups answer questions. This process strives to realize interns' personal value and find their blind knowledge during the process of communication so as to study related knowledge.

Laboratory Science consulting service not only exercises interns' ability of communicating with patients, but also it urges and guides students to study autonomously and actively, enhances their initiative and enthusiasm, exercises their clinical thinking ability, cultivates their ability of finding problem, thinking problem and solving problem, laying a solid foundation for becoming a qualified tester .

\subsection{WeChat Platform Sever Push}

The WeChat platform offers a 'push' function of active release. In practical application, it can push related common sense, new technology popularization, medical knowledge and other related medical knowledge by subscription account, through which strengthen overall quality and health awareness of the public. Collecting medical frontier information partly depends on interns, and related thematic knowledge push will be done regularly. It is expected to through interns' active participation, motivate them to carry out a prospective study on changing frontier of laboratory science, polish up their scientific eyes, have the ability of finding new knowledge and new areas, laying foundation for their future work in science, education and research.

\section{4. “Flipping Classroom" to Transform Our Role}

In order to enhance teaching efficiency and optimize teaching resources, our hospital makes the "flip classroom" module on the basis of WeChat platform. That is, students can decide their own learning process by watching the micro-class made by the teacher through the micro-platform., realizing teaching students according to their aptitude .While watching the teaching videos, students can deepen their impressions according to the emphasis (or key points) of the course, have a systematic understanding of relevant knowledge in the process of learning and communicate with others about their problems online or offline. At the same time, students who have confusions can play repeatedly, so that learning can be more solid and becomes the new norm for students to learn independently. Micro-course offline learning makes students' learning atmosphere more lively, lovely and free. In the "flipping classroom", infinite repetition and reversibility are a great convenience for students to learn so that students can enjoy almost absolute equality of learning opportunities and space, and put the implementation of teaching according to their aptitude into practice. This kind of face-to-face interaction between students and students, students and teachers can achieve the educational goals of deep learning, cultivating students' problem-solvin , creative thinking, high-level reasoning and critical thinking ability [14]. At the same time, vast online resources sharing makes the course study more stateless, and can provide a wider academic exchange platform for interns in the future. This teaching method will better make students active from being passive, promote students to internalize scattered knowledge points into systematic knowledge, so that they can learn and communicate anytime and anywhere, anytime and anywhere. Therefore, Medical Laboratory are bound to thrive and abound.

\subsubsection{Collecting Information and Making Teaching Video}

Before making teaching video, the teacher needs to sort out the practical and theoretical problems which is existed in the internship process and make a record (including the problems that the intern is aware of and detailed problems that the intern unconsciously committed). In view of these problems and combined with the clinical experience of teachers, the corresponding teaching video can be made. Video can be demonstrated from the following aspects: wrong demonstration, wrong cause, correct operation, combination of clinical and summarization. In addition, certain phonetic teaching can be combined to let interns see their essence through the phenomenon of the problem.

\subsubsection{Preparing Before Micro Class}

Before the students watch micro class, the teacher should publish the general content in the WeChat group of interns, so that the interns can know what they have learned in advance. In this way, it is a process of second learning when watching micro class video. It plays the role of checking omissions and filling in gaps, so as to make its grasp of knowledge more profound.

\subsubsection{Micro Communication}

When the students watch the micro process, they can take the form of group discussion: group members (3-4 people in each group) can be whispered discussion and will discuss the problem and the results recorded in the notebook, micro lesson after the group sent representatives will discuss the relationship between content to the classroom for group discussion, the teacher as spectators appropriate help, to create a strong learning atmosphere.

\subsubsection{The Summary of Micro Class}

After the discussion among the groups, the teacher will ask questions and the group members will answer them. The extra points system can be implemented, and the extra points can be given according to the overall level of the answers. At last, the teacher made a summary of the micro course teaching and the intern sent the micro course video to the public account of WeChat for people to learn repeatedly. 


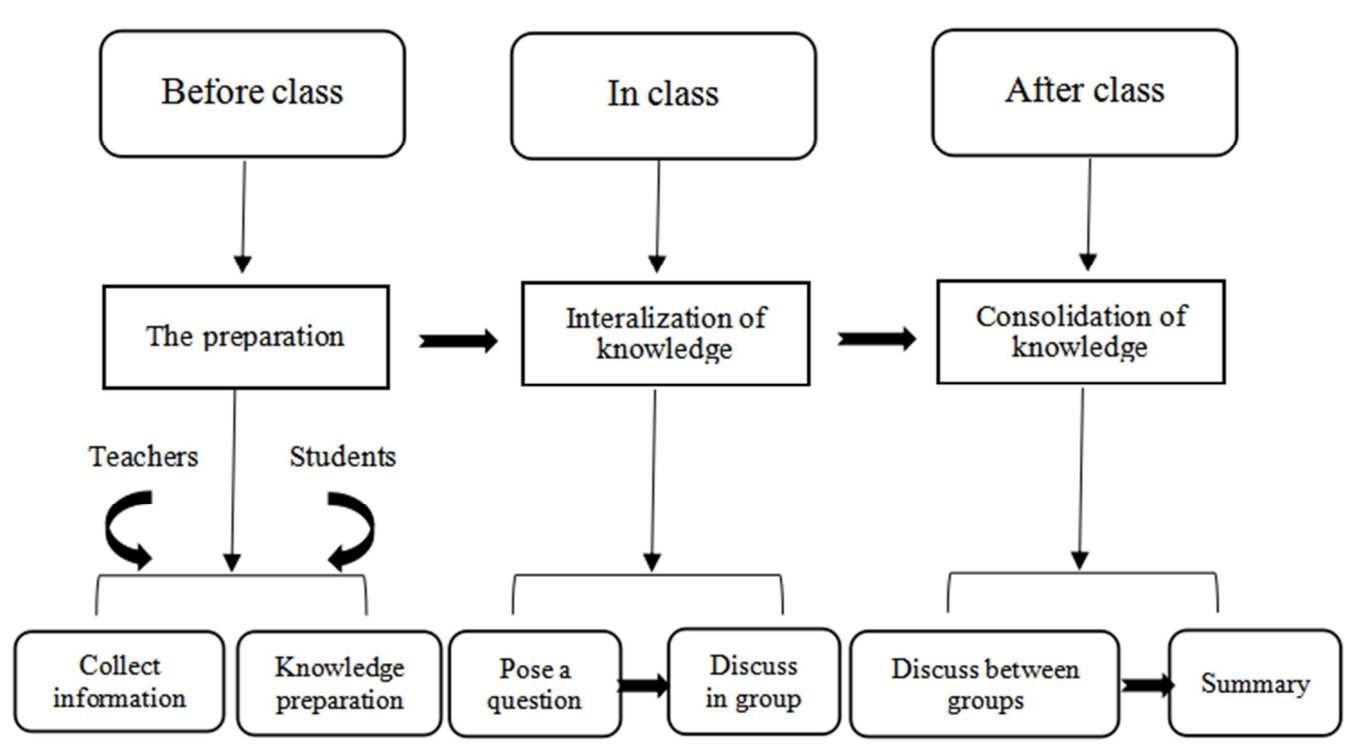

Figure 2. Flipping classroom design.

\subsection{Clinical Interactive Consultation Module (Under Construction)}

WeChat's basic functions provide voice text interaction and group chat. Basing the convenient function of message interaction between the WeChat friends, groups, users and official account, our department builds a distant consultation platform on the basic of this function, so as to provide laboratory medicine support service in terms of clinical treatment process, relative project questions and so on, integrate laboratory medicine into the clinic and serve patients better.

Through clinical rotation, we have found the serious disconnection between testers and clinic, testers and patient about service and needs [15]. Clinical interactive consultation seeks to provide laboratory medical advice for clinic on the basis of the construction of distant consultation, and change the passive test work into active clinical test and diagnosis. The module is in the charge of senior test team leaders. Interns of Laboratory Science and related personnel wil attend. Through clinical case discussion, clinical consultation discussion and other forms of communication, it intends to equip them with clinical diagnostic thinking mode, and the ability to communicate with clinic, enhance their activity of clinical practice, and exercise their ability of clinical thinking.

\section{Discussion}

Laboratory Science interns teaching is a hit for every generation of testers. How to pass the clinical experience of older generation to inferiors and make the new generation of testers realize the true meaning of Laboratory Science in a relaxed and happy internship is a key point which we have been thinking about and innovating. The new mode of applying WeChat platform to teaching is intended to mobilize the enthusiasm, curiosity, sense of responsibility and sense of mission of the interns, so that they can improve their academic and knowledge level and enhance their clinical communication ability in a relaxed and happy atmosphere, making them a new generation of excellent testers.

Laboratory Science WeChat official account service is a new service mode, which integrates Laboratory medicine into the clinical work better from a new thinking mode, and sets up communication platform between testers and patients, testers and the clinic by means of particular advantages of the WeChat platform. Through the operation of the " $3+1$ " WeChat platform mode, it is expected that more and more people are bound to benefit from the development of laboratory medicine, and the booming laboratory medicine will serve the society and the public better.

\section{Expectation}

With the rapid development of information and internet technology, students' learning is not limited to the classroom, books. Mobile phones and computers are available for us and become good helpers for learning. The Internet makes the whole world a global village. Similarly, with the advent of the big data era, sharing medical knowledge on the network is no longer an empty talk. Big data connects Clinical Medicine, Medical laboratory, Medical Imaging, and other diverse disciplines together to create a framework for massive medical data that allows interns and even teachers to search for information they need whenever and wherever they want and learn about knowledge of the frontiers of medical care. To a certain extent, it can improve the diagnostic accuracy, reduce the incidence of accidents, and realize remote monitor of patients' treatment status, thus providing more advanced treatment for patients. It will be a milestone in the medical industry! At present, on the basis of "flipping classroom", we accumulate practical experience, further improve the preliminary work of big data, turning ourexpectations into reality. I believe that in the foreseeable future, big data will be popularized among hospitals and international integration is no longer an expectation. 


\section{References}

[1] X. Ting, R. G. dong, C. Dan, Z. Hong, Z. J. Xin, H. P. Jun, G. Bing (2015), "Exploration of new teaching mode in undergraduate clinical practice of laboratory medicine,". China medical herald, Vol.12, No.16, pp.84-88.

[2] P. J. Gang, Z. Z. Ying, Y.X.Ying (2005), "PROGRESSES ON MICROMACHINED FLOW SENSORS BASED ON MEMS TECHNOLOGIES,"ADVANCES IN MECHANICS.Vol.3, pp.361-376.

[3] C. L. Jun, L. Bin, M. L. Na (2011), "Thinking about the status of faculty during clinical teaching of medical students,"Chin J of Med Edu Res, September, Vol.10, No.9, pp.1034-1036.

[4] Z. X. lin, H. Fang (2011), "Test the problems and countermeasures of practice teaching,".Lab.Med Clin, August , Vol.8, No.16, pp.2035-2036.

[5] Zhou L, Xiaolong X U, Urology D O. (2018) The Application and Experience of PBL Mode Combined With WeChat Platform in Urology Teaching Process [J]. China Continuing Medical Education.

[6] Zhou C, Peng Y M, Deng S J (2018). Application effect of We Chat public platform in nursing teaching of oper-ating room [J]. China Modern Medicine.

[7] Shu H S, Wang D W, Chao Q (2018). Research on Application of Flipping Classroom Combined with Wechat Platform and Medical Resource APP in Neurosurgery Teaching [J]. Medical Information.

[8] Yang F, Wei J, Liu C (2018). Research on Individualized Teaching Service Based on WeChat Public Platform [J]. China Computer \& Communication.

[9] S. Jing, D. C. Bo, Z. B. Yu, T. X, M. Li , Y. P. Lin (2014), “A preliminary study on the influence evaluation of the weibo WeChat platform in scientific and technological journals,". Journal of science and technology of China. vol 5.

[10] W. Ping (2014), "Construction and Application of WeChat Mobile Learning Platform,"Modern Educational Technology.Vol.5, pp.88-95.

[11] W.Ping (2013),"Analysis of Support Functions and Design Principles of Mobile Learning Based on WeChat,"Distance Education Journal.November, Vol.6, pp.34-41.

[12] Z.Ping, Z.W.Shuo (2017),"Flipped Classroom: Theory, Development History and Effectiveness,"Journal of Educational Studies. Vol.1, pp.46-55.

[13] H.Wei (2016)," Create a new pattern of inspection service with WeChat platform," International Journal of Laboratory Medicine, Vol.12, pp.1744-1745.

[14] Jia-Xin L I, Xiao-Jing L I, Wei C H (2018). The Application of Blended Teaching Model Based on WeChat Public Platform in the Course of Medical Biochemistry [J]. Medicine Teaching in University.

[15] Pan R, Yuntao J I, Pharmacy D O.(2018) The Practice and Exploration of the Teaching Method of the New Case Teaching in Clinical Pharmacy Undergraduate Interns [J]. China Continuing Medical Education. 